\title{
Rancang Bangun Robot Pengangkut Sampah pada Kanal Sempit
}

\author{
Muhtar $^{1 *}$, Rafiuddin Syam ${ }^{1}$, Zulkifli Djafar ${ }^{1}$ \\ ${ }^{1}$ Departemen Teknik Mesin, Fakultas Teknik, Universitas Hasanuddin, Makassar \\ Jl. Poros Malino km. 6, Bontomarannu, Kabupaten Gowa, Sulawesi Selatan 92171 \\ *Email: muhtar_st@yahoo.com
}

DOI: 10.25042/jpe.112018.05

\begin{abstract}
Abstrak
Salah satu penyebab terjadinya banjir adalah faktor sampah yang banyak tersebar di kanal. Salah satu cara mengatasinya adalah dengan membuat robot pengangkut sampah pada kanal sempit. Adapun tujuan penelitian ini adalah merancang sebuah model robot pengangkut sampah pada kanal dan mampu membuat program arduino dalam mengopersikan robot tersebut. Bagian-bagian robot ini adalah rumah robot, rangka pengangkut sampah, pengangkut sampah, motor penggerak sistem, roda pengerak, arduino uno dan perangkatnya serta aki. Prinsip kerja robot ini adalah program memberi printah kerja pada sistem atau motor penggerak untuk menggerakkan rangka pengangkut sampah bergerak turun ke kanal untuk menemukan air. Di saat sensor air telah menyentuh air maka sensor akan mengirim ke program agar memberhentikan motor penggerak rangka pengangkut sampah. Bersamaan dengan itu, program memerintahkan/mengirim sinyal ke motor penggerak pengangkut sampah (jaring-jaring dan bilah pipa) agar berputar, sehingga bergerak menyaring sampah yang ada. Pada penelitian ini robot pengangkut mampu mengangkat sampah $5 \mathrm{~kg}$ sehingga diproleh torsi mesin $7,5 \mathrm{~kg} . \mathrm{cm}$ dan Daya sebesar 117,75 Watt. Sedangkan menurut perhitungan mesin robot ini mampu mengangkat sampah sebesar 66,7 kg memiliki torsi sebesar 100 kg.cm dan daya sebesar 14401,7 watt
\end{abstract}

\begin{abstract}
Design of Robot Transporting Garbage in Narrow Canals. One of the causes of flooding is the waste factor that is widely spread in the canal. One way to overcome this is to make a robot transporting garbage on a narrow canal. The purpose of this research is to design a model robot garbage transporter on the channel and able to make arduino program in operation this robot. Parts of this robot is a house of robot, garbage truck, garbage haul, motor drive system, wheel pemer, arduino uno and its devices and batteries. The working principle of this robot is a program send signals to system or motor drive to move the frame moving the waste down to the canal to find water. When the water sensor has touched the water, the sensor will send to the program to stop the motor driving the truck carrying garbage. At the same time, the program commands/sends signals to the garbage transporting motor (the webs and pipes) to rotate, so that it moves through the existing waste. In this research, the robot transporter is able to lift $5 \mathrm{~kg}$ of waste. So, the engine torque is $7.5 \mathrm{~kg} . \mathrm{cm}$ and the power is 117.75 Watt. But according to calculations robot machine is able to lift the garbage of $66.7 \mathrm{~kg}$ has a torque of 100 kg.cm and power of 14401.7 watts
\end{abstract}

Kata Kunci: Kanal, motor, sensor, torsi

\section{Pendahuluan}

Berdasarkan definisinya, sampah adalah buangan yang dihasilkan dari suatu proses produksi baik industri maupun domestik atau rumah tangga. Adapun definisi sampah menurut undang-undang nomor 18 tahun 2008 tentang pengelolaan sampah bahwa sampah adalah sisa kegiatan sehari-hari manusia atau proses alam yang berbentuk padat atau semi padat, berupa zat organik atau anorganik bersifat dapat terurai atau tidak dapat terurai yang dianggap tidak berguna lagi dan dibuang ke lingkungan [1].
Menurut liputan 6.com jumlah sampah di kota Makassar pada tahun 2016 sekitar 700-800 ton perhari, jauh lebih meningkat dari tahun sebelumnya. Pada tahun 2015 jumlah sampah yang masuk di TPA Tamangapa sekitar 400 ton. Jumlah sampah yang masuk ke TPA tahun 2016 ini meningkat drastic. Hal itu disebabkan karna hampir seluruh sampah yang berada di lorong atau gang sudah terjamah petugas kebersihan dan semuanya dibawah masuk atau dibuang ke TPA Tamangapa, kecuali sampah-sampah yang terdapat pada kanal-kanal atau got belum maksimal terangkut. Melihat kondisi ini kami 
bermaksud mendesain alat pengangkut sampah agar memudahkan pengangkutan sampah dari kanal-kanal yang sempit (got) demi terwujudnya Makassar Tidak Rantasa.

\section{Tinjauan Pustaka}

Kata Robot berasal dari bahasa Czech "ROBOTA" yang artinya pekerja budak. Istilah robot dikenalkan oleh Karel Capek pada tahun 1921. Penggunaan kata ROBOT dikenalkan oleh Capek dengan menjadikan kata itu nama perusahaannya, Rossum Universal Robot (RUR) pada bulan Januari 1921. Perbedaan mendasar dari Mekatronika dan Robotika adalah dari derajat kebebasan geraknya. Derajat Kebebasan atau DOF (Degree of Freedom) dari peralatan/mesin yang didefinisikan sebagai mekatronika maksimal 2. Sedangkan DOF untuk peralatan/mesin yang didefinisikan sebagai robot haruslah mempunyai lebih dari 2 DOF Dari berbagai litelatur robot dapat didefinisikan sebagai sebuah alat mekanik yang dapat diprogram berdasarkan informasi dari lingkungan (melalui sensor) sehingga dapat melaksanakan beberapa tugas tertentu baik secara otomatis ataupun tidak sesuai program yang di inputkan berdasarkan logika [2].

Berikut ini merupakan skema dari dasar-dasar robotika:

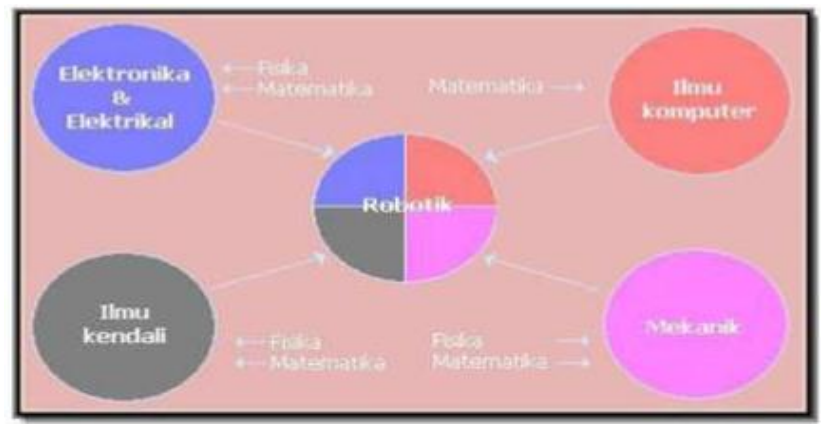

Gambar 1. Skema dasar-dasar robotika

Robot pada awalnya diciptakan untuk menggantikan kerja manusia untuk sesuatu yang berulang, membutuhkan ketepatan yang tinggi dan juga untuk menggantikan manusia bila harus berhubungan dengan daerah berbahaya. Penggunaan robot lebih banyak terletak pada industri, misalnya untuk proses welding pada industri otomotif. Selain pada industri, penggunaan robot semakin berkembang luas. Seiring berkembangnya teknologi, berbagai robot dibuat dengan spesialisasi atau keistimewaan tertentu. Robot dengan keistimewaan tertentu sangat erat kaitannya dengan pemenuhan kebutuhan dalam dunia industri modern, dimana industri modern menuntut adanya suatu alat dengan kemampuan tinggi yang dapat membantu menyelesaikan pekerjaan manusia ataupun menyelesaikan pekerjaan yang tidak mampu diselesaikan manusia. Tidak semua robot memiliki jumlah dan jenis komponen yang sama. Jenis dan jumlah komponen utama robot sangat tergantung pada jenis tugas apa yang akan dilakukan [3]. Berikut komponen robot secara umum:

\subsection{Manipulator}

Manipulator merupakan sistem mekanik yang menunjukkan pergerakan dari robot. Sistem mekanik ini terdiri dari susunan link (rangka) dan joint (sendi) yang mampu menghasilkan gerakan yang terkontrol, sebagai rangakaian umpan balik terbuka maupun rangkaian umpan balik tertutup yang dihubungkan dengan sendi-sendi dan dapat melakukan gerakan-gerakan secara bebas. Beberapa istilah dalam manipulator robot yaitu:

- Joint (sendi) yaitu koneksi antar link yang dapat menentukan pergerakan. Pada Gambar 2 berikut merupakan contoh joint (sendi) pada robot

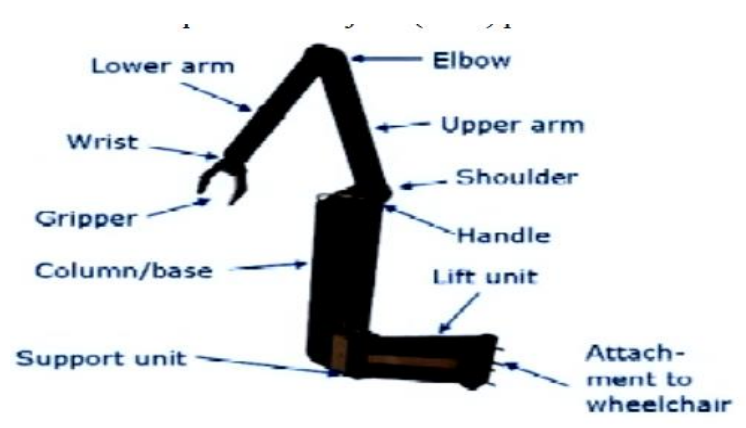

Gambar 2. Join atau sendi pada robot

- Link merupakan bagian-bagian kerangka yang kaku yang dihubungkan secara bersamaan sehingga membentuk suatu rangkaian kinematik [4]. 
Bagian dasar manipulator terpasang secara permanen pada lantai area kerja ataupun terpasang pada rel. Rel berfungsi sebagai path atau alur sehingga memungkinkan robot untuk bergerak dari satu lokasi ke lokasi lainnya dalam satu area kerja. Bagian tambahan merupakan perluasan dari bagian dasar, bisa disebut juga lengan atau arm. Bagian ujungnya terpasang pada end efektor yang berfungsi untuk mengambil atau mencekam material. Manipulator digerakkan oleh aktuator atau disebut sistem drive yang menyebabkan gerakan yang bervariasi dari manipulator.

\subsection{Notasi Denavit Hartenberg}

Untuk membentuk persamaan lengan robot berjenis articulated robot, digunakan notasi Denavit-Hertenberg. Notasi ini mendeskripsikan parameter hubungan antara satu sendi/lengan dengan sendi/lengan lainnya. Notasi ini terdiri atas 4 parameter yaitu $a_{i}, \alpha_{i}, d_{i}$, dan $\theta_{i}$ dan dituliskan pada sumbu XYZ. Gambar berikut memperlihatkan posisi notasi tersebut:

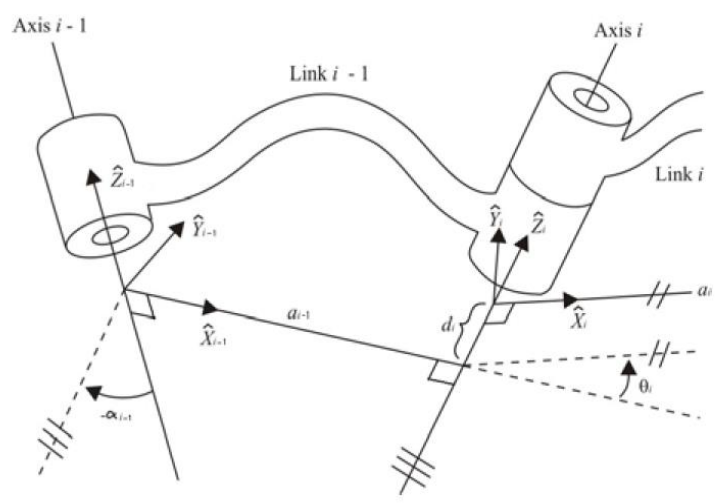

$a_{i}=$ jarak dari $Z_{i}$ ke $Z_{i+1}$ diukur sepanjang $X_{i}$ $\alpha_{i}=$ sudut antara $Z_{i}$ ke $Z_{i+1}$ diukur seputar $X_{i}$ $\mathrm{d}_{\mathrm{i}}=$ jarak dari $X_{\mathrm{i}-1}$ ke $X_{\mathrm{i}}$ diukur sepanjang $Z_{\mathrm{i}}$ $\Theta_{\mathrm{i}}=$ sudut antara $X_{\mathrm{i}-1}$ ke $X_{\mathrm{i}}$ diukur seputar $Z_{\mathrm{i}}$

\section{Gambar 3. Notasi denavit hartenberg}

Dengan notasi tersebut posisi sebuah sendi yang terdapat pada ujung akhir sebuah lengan dapat dihitung berdasarkan posisi sending ujung awal lengan, sudut sendi, dan panjang lengan. Karena sebuah sendi menghubungkan antara sebuah lengan dengan lainnya maka posisi end effector yang pada simulator ini dimodelkan dengan sebuah gripper yang dapat dihitung [5].

\subsection{Mobile Robot}

Pada saat ini, telah ada sistem yang mampu mengontrol gerak robot pada area tidak teratur atau banyak rintangan [4]. Dalam hal ini ada banyak temuan dan aplikasi dalam hal ini yang mampu mengontrol roboit tersebut. Misalnya, NASA adalah menggunakan mobile robot untuk mengeksplorasi permukaan Mars [6]. Area yang tidak teratur mungkin memiliki beberapa rintangan. Untuk alasan ini, roda mobile robot harus mampu mendeteksi lingkungan/ atau area. Untuk ini, sensor ultrasonik dan sistem stereovision harus berada di dalam mobile robot untuk memberikan kontrol. Pada tahap mekanisme pergerakan robot, perangkat sensor memungkinkan pengembangan strategi kontrol untuk menyelesaikannya ketika robot harus berurusan dengan masalah yang kompleks. Ketika robot bergerak menuju target dan mendeteksi ada hambatan atau kemiringan, perlu cara untuk menghindarinya. Untuk proses yang efektif dari robot cerdas, robot dilengkapi dengan sistem pengenalan area dan sistem untuk menganalisis situasi, membuat keputusan, dan melakukan perencanaan [7].

\subsection{Ujung (end efector)}

End effector berfungsi sebagai bagian terakhir yang menghubungkan antara manipulator dengan objek yang akan dijadikan kerja dari robot. End effector jika disamakan dengan manusia seperti jari-jari tangan yang dapat digerakkan untuk memindah atau mengangkat material ataupun peralatan yang dapat digunakan untuk mengelas, mengecat, menempa, mengisi botol dan lain-lain sesuai dengan kebutuhan. Bentuk efektor banyak memiliki banyak jenis, salah satunya adalah gripper [2].

\subsection{Pengendali (Controller)}

Kontroler merupakan jantung dari sistem robot sehingga keberadaannya sangat penting. Kontroler menyimpan informasi yang berkaitan dengan data-data robot, dalam hal ini data gerakan robot yang telah diprogram sebelumnya. 


\section{Metode Penelitian}

Penelitian yang kami lakukan diawali dengan proses desain yang terbagi atas dua bagian utama, yaitu desain sistem mekanik yang kemudian dilanjutkan dengan proses mendesain rangka sebagai tempat tumpuan pada saat sistem mekanik bekerja.

Adapun desain robot pengangkut sampah pada kanal sempit yang telah kami rancang pada penelitian ini dapat dilihat pada gambar berikut:

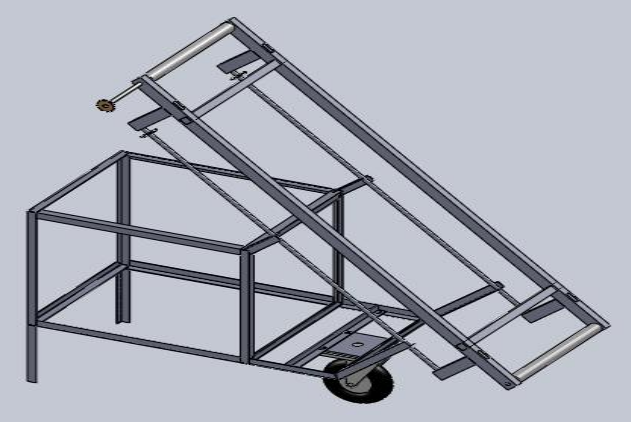

Gambar 4. Desain robot pengangkut sampah pada kanal sempit

Adapun dimensi robot tersebut sebagai berikut:

\subsection{Rumah robot}

Rumah robot terbuat dari besi siku dengan dimensi panjang $50 \mathrm{~cm}$, lebar $40 \mathrm{~cm}$ dan tinggi 50 $\mathrm{cm}$ dengan dinding terbuat dari plat aluminium dengan alas terbuat dari kawat jarring-jaring diameter $5 \mathrm{~mm}$. besi siku-besi siku yang berjumlah 12 potongan itu dihubungkan membentuk rangka bak sampah. Ujung-ujung besi siku tersebut dihubungkan satu sama lain melalui proses pengelasan. Seperti pada Gambar berikut:

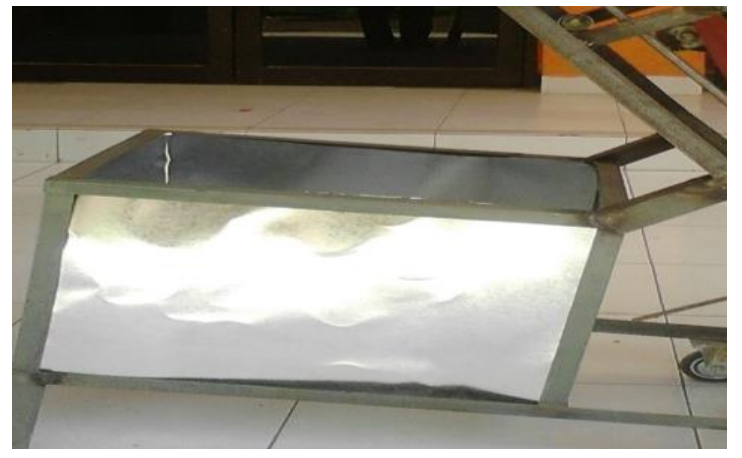

Gambar 5. Rumah robot pengangkut sampah kanal sempit

\subsection{Rangka Pengangkut Sampah}

Rangka pengangkut sampah dengan ukuran $120 \mathrm{~cm} \mathrm{x} 40 \mathrm{~cm}$. penyangga utama terbuat dari besi holo dengan dimensi panjang $120 \mathrm{~cm}$, lebar 2 $\mathrm{cm}$ dan tinggi $3 \mathrm{~cm}$. kedua ujung besi holo tersebut dihubungkan dengan roda gigi sepeda bersama dudukannya baik pada rangka sebelah kiri maupun sebelam kanan. Kedua roda gigi tersebut dihubungkan agar membentuk sebuah poros dari suatu rangka pengangkut sampah. Untuk memudahkan pergerakan poros tersebut maka pada kedua ujung besi dipasang bearing. Berdasarkan poros yang dipakai dengan diameter $14 \mathrm{~mm}$, maka jenis bantalan yang sesuai untuk digunakan dalam mendesain stand conveyer robot ini adalah bantalan gelinding dengan nomor bantalan $6304 \mathrm{ZZ}$, ukuran diameter dalam (d) = $15 \mathrm{~mm}$, diameter luar $(\mathrm{D})=30 \mathrm{~mm}$, lebar $(\mathrm{B})=$ $10 \mathrm{~mm}$, jari-jari bola $(\mathrm{r})=2 \mathrm{~mm}$. untuk lebih jelasnya dapat dilihat pada Gambar berikut:

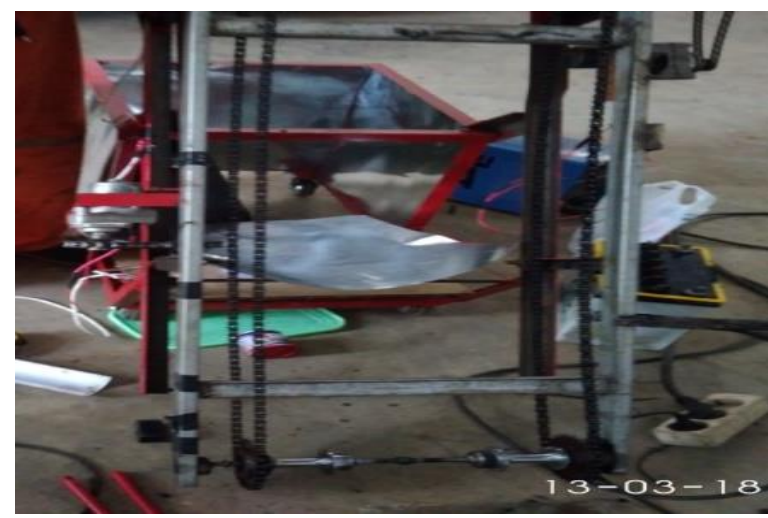

Gambar 6. Rangka pengangkut sampah kanal sempit

Roda gigi tersebut dihubungkan dengan rantai sepeda agar dapat berputar yang nantinya dapat menaikturunkan penjaring sampah pada kanal. Setelah rantai terpasang pada sisi kiri dan kanan maka rantai tersebut dihubungkan dengan jaring jaring agar membentuk seperti sebuah konveyor yang dapat bergerak. Agar pengangkutan sampah maksimal maka pada bagian atas jaring-jaring dipasang bilahan pipa. Sebagai penggerak rangka pengangkut sampah, pada ujung poros rangka tersebut dipasang roda gigi dengan diameter $6 \mathrm{~cm}$ yang dihubungkan dengan motor DC 12 Volt $4 \mathrm{~A}$ melalui rantai penggerak. Pada poros motor juga dipasang roda gigi dengan diameter $2 \mathrm{~cm}$, motor 
tersebut dipasang pada rangka pengangkut sampah yaitu pada batang besi holo.

Untuk memperluas medan jangkaun dari pengangkut sampah ini maka rangka ini bergerak naik turun dengan kemiringan 45 derajat. Adapun sistem yang digunakan dalam pergerakan tersebut adalah sistem ulir, yaitu dengan memasang pada bagaian bawa rangka tersebut ulir sepanjang $100 \mathrm{~cm}$ yang bertumpu pada besi siku yang dipasang dibawah penyangga rangka. Untuk menggerakkan ulir tersebut maka kedua ulir tersebut dipasangi dengan roda gigi yang dihubungkan ke motor penggerak DC 12 Volt 4 A melalui rantai penggerak. Motor tersebut dipasang pada batang besi rangka pengangkut sampah. Untuk menghindari gesekan antara rangka pengangkut sampah dengan penumpu besi holo maka dipasang empat buah bearing yang berfungsi sebagai roda rangka pengangkut sampah saat pergerakan naik turun.

\subsection{Roda Penggerak}

Untuk memudahkan proses pergerakan robot baik untuk maju mundur maupun kiri kanan maka pada bagian depan robot dipasang dua buah roda putar yang terbuat dari karet tebal $10 \mathrm{~cm}$ dengan peleg $10 \mathrm{~cm}$. roda ini juga berfungsi sebagai penyangga bagian depan robot. Adapun penyangga bagian belakang maka dipasang dua bauh roda dengan diameter $10 \mathrm{~cm}$.

\subsection{Motor Penggerak}

Adapun motor penggerak yang digunakan pada penelitian ini adalah Motor DC Geared Kursi Roda dengan spesifikas sebagai berikut:

- Built - in gearbox

- V suplai : DC 12 Volt

- Arus : 4 Amper

- Speed : $500 \mathrm{rpm}$

- Torsi : 100 kg.cm

- Dimensi body : panjang 12,5 $\mathrm{cm}$ dengan diameter $5 \mathrm{~cm}$

- Dimensi shaft : panjang 1,5 cm dengan diameter $1,5 \mathrm{~cm}$

- Berat motor ; 930 gram

- Aplikasi : penggerak kursi roda elektrik, chair wheel transformer, motor lawn movered
- $\quad$ Sudut ulir $(\alpha)=4^{\circ}$

- $\operatorname{Massa} \operatorname{sampah}(\mathrm{P})=5 \mathrm{~kg}$

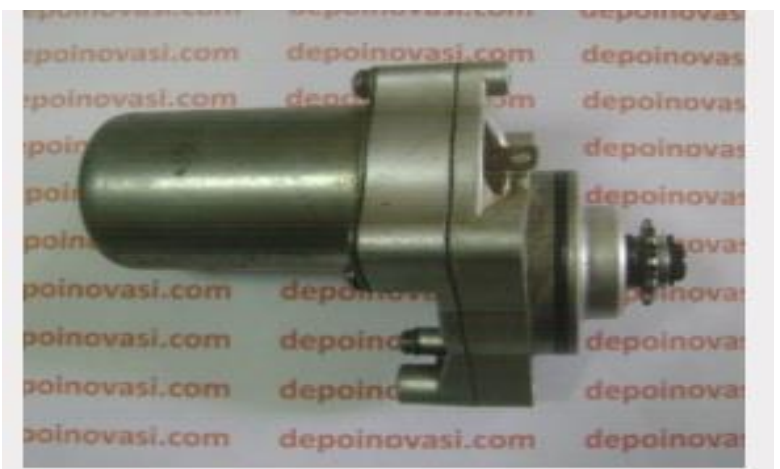

Gambar 7. Motor penggerak robot pengangkut sampah

\subsection{Micro Controller Universal}

Pada penelitian ini Microcontroller yang digunakan adalah Arduino Uno. Berikut ini Gambar model arduino uno:

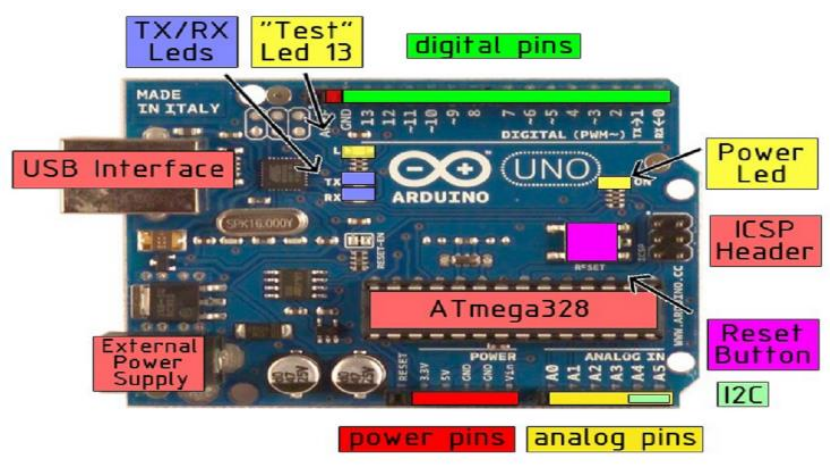

Gambar 8. Perangkat arduino uno

\subsection{Sensor air}

Sensor air digunakan untuk mendeteksi adanya air. Terdapat serangkaian konduktor parallel pada sensor yang dapat mendeteksi air. Output sensor ini adalah adanya sinyal analog yang akan dibaca oleh MCU seperti arduino uno untuk selanjutnya diolah agar diketahui kedalaman air. Adapun sensor air yang diapakai pada penelitian ini adalah Water Level Sensor dengan spesifikasi sebagai berikut: tegangan 3-5 $\mathrm{V}$ (DC), konsumsi arus $20 \mathrm{~mA}$, tipe analog, area deteksi $40 \mathrm{~mm} \times 16 \mathrm{~mm}$, tempertur kerja $10^{\circ} \mathrm{C}$ sampai $-30{ }^{\circ} \mathrm{C}$, kelembaban $10-90 \%$, massa $3,5 \mathrm{~g}$, dimensi $62 \times 20 \times 8 \mathrm{~mm}$. 


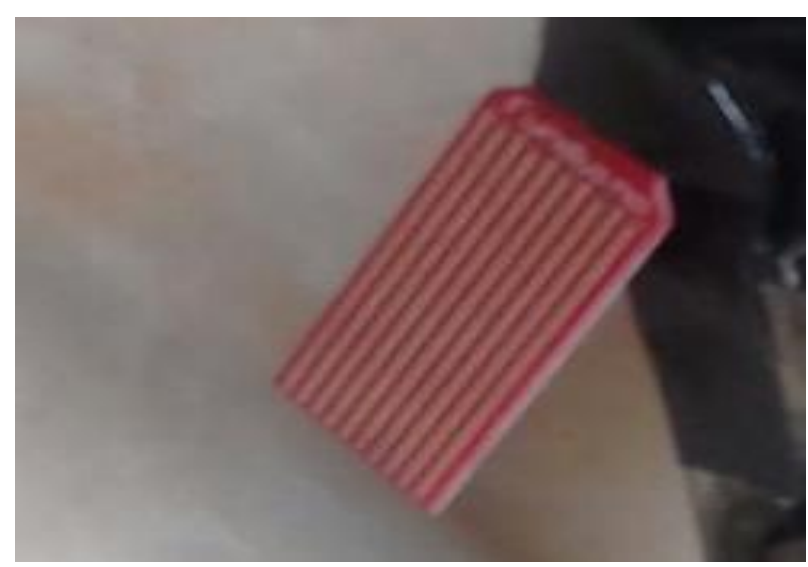

Gambar 9. Water level sensor

\section{Hasil dan Pembahasan}

Pada penelitian ini telah berhasil dibuat rancangan robot pengangkut sampah seperti pada Gambar 4.

\subsection{Program Arduino Uno}

Setelah bodi robot selesai didesain maka langkah selanjutnya adalah membuat program pada software arduino uno. Adapun programnya sebagai berikut:

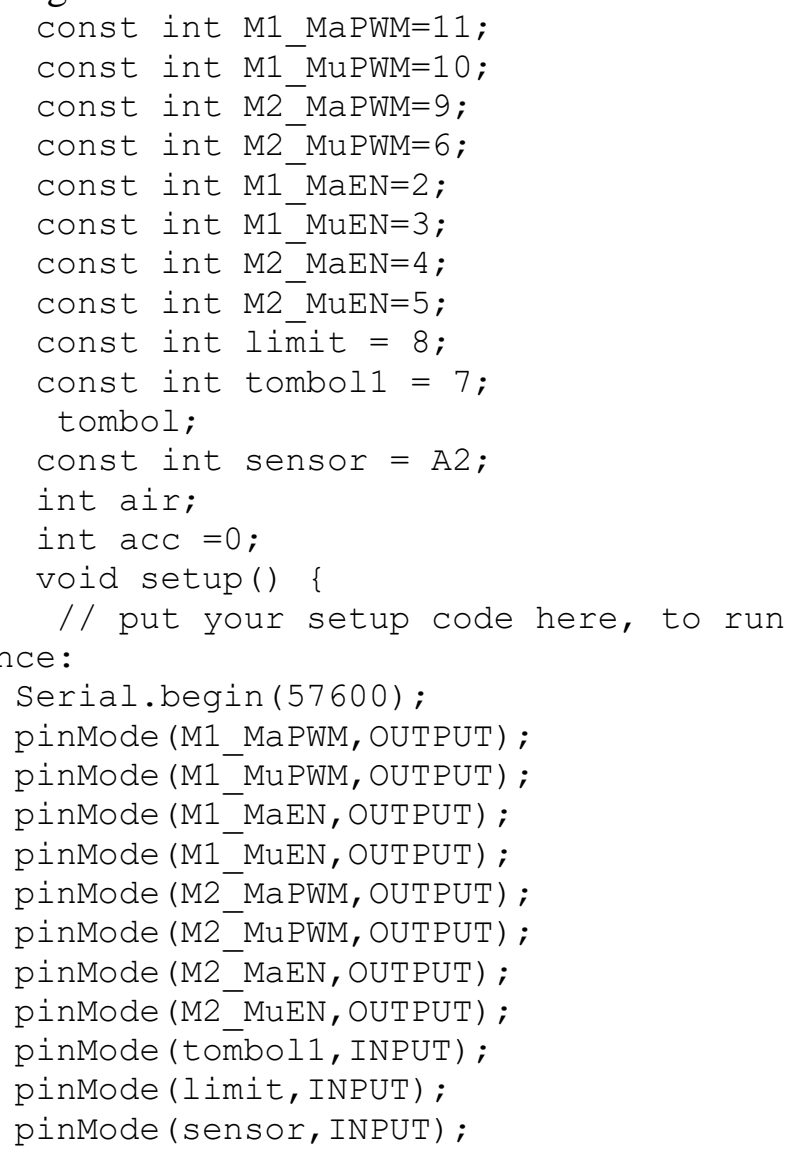

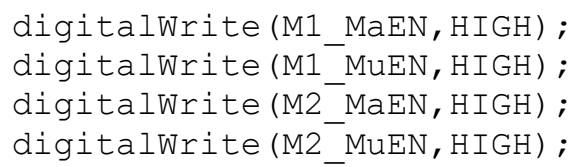

Program ini berhasil menjalankan robot sesuai yang diinginkan.

\subsection{Prinsip Kerja Robot}

Adapun prinsip kerjanya sebagai berikut: Prinsip kerja robot ini adalah bekerja dengan menaik-turunkan rangka pengangkut sampah kedalam kanal untuk mengangkut sampah. Proses ini dilakukan dengan dengan memasang sensor pada ujung bawa rangka ini berupa sensor pendeteksi air yaitu sensor air dari arduino. Cara kerjanya adalah arduino akan memberi sinyal kepada motor untuk menggerakkan rangka sampai menemukan air. Ketika ujung rangka sudah menyentuh air maka sensor air akan menghentikan motor, dan mengirim sinyal kepada motor pemutar bagian pengangkut sampah agar berputar menyaring sampah yang ada pada kanal untuk diangkut ke atas lalu diturunkan pada talang yang berada pada bagian belakang robot pengangkut sampah.

\subsection{Torsi dan Daya Robot}

Adapun torsi dan daya dari robot ini adalah: Menurut data pada motor yang digunakan besarnya beban yang dapat diangkat adalah $w=\frac{T}{d \text { motor }}=\frac{100}{1,5}=66,7 \mathrm{~kg}$ sehingga gaya yang dihasilkan adalah $F=m \times g=66,7 \times 10=667 \mathrm{~N}$.

Jadi robot ini mampu mengangkat sampah sampai kurang lebih $67 \mathrm{~kg}$. Pada penelitian yang telah kami lakukan robot hanya dibebani maksimal $5 \mathrm{~kg}$ sampah sehingga torsi pada beban ini adalah

$$
T=m \times d=5 \times 1,5=7,5 \mathrm{~kg} . \mathrm{cm}
$$

Adapun daya pada motor atau robot ini adalah

$$
\begin{aligned}
\text { Power } & =T \times 2 \pi \times n \\
& =100 \mathrm{~kg} . \mathrm{cm} \times 3,14 \times 500 \mathrm{rpm} \times 9,81 \times 10^{-2} \\
& =15401,7 \text { Watt }
\end{aligned}
$$


Sedangkan daya pada saat penelitian adalah

$$
\begin{aligned}
\text { Power } & =T \times 2 \pi \times n \\
& =7.5 \mathrm{~kg} \cdot \mathrm{cm} \times 3,14 \times 500 \mathrm{rpm} \times 10^{-2} \\
& =117,75 \text { Watt }
\end{aligned}
$$

\subsection{Hubungan Putaran, Kecepatan dan Daya Pada} Motor dan Sistem

Berdasarkan pengolahan data didapatkan bahwa putaran motor memiliki pengaruh yang begitu besar dengan kecepatan dan daya yang dihasilkan oleh motor dan sistem. Putaran motor memberikan pengaruh yang begitu besar dengan kecepatan motor. Untuk lebih jelasnya hubungan antara putaran motor dengan kecepatan dapat dilihat pada Gambar berikut:

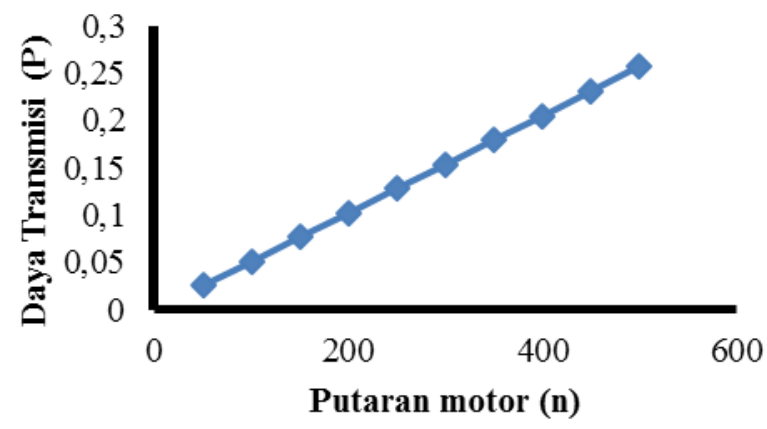

Gambar 10. Grafik hubungan antara putaran motor dengan kecepatan motor

Berdasarkan grafik di atas dapat dijelaskan bahwa putaran motor berbanding lurus dengan kecepatan yang dihasilkan oleh motor. Hal ini disebabkan karena kecepatan motor bergantung pada besar kecilnya putaran motor. Putaran motor yang bervariasi dan cenderung meningkat dengan diameter yang tetap akan memberikan kecepatan motor yang besar. Putaran motor adalah variabel yang sangat mempengaruhi waktu dalam proses permesinan atau penggunakan motor. Dengan putaran motor yang besar akan memberikan waktu yang lebih sedikit sehingga hal ini berpengaruh pada kecepatan yang dihasilkan.

Di samping itu, putaran motor juga sangat berpengaruh terhadap daya yang ditransmisikan ke sistem dalam hal ini berpengaruh terhadap kemampunan atau daya yang digunakan untuk menggerakkan rangka pengangkut sampah dan kemampuan mengangkut beban dari kanal. Hal ini disebakan karena daya yang ditransmisikan ke pengangkut sampah sangat dipengaruhi oleh kecepatan motor. Untuk lebih jelasnya dapat dilihat pada Gambar berikut:

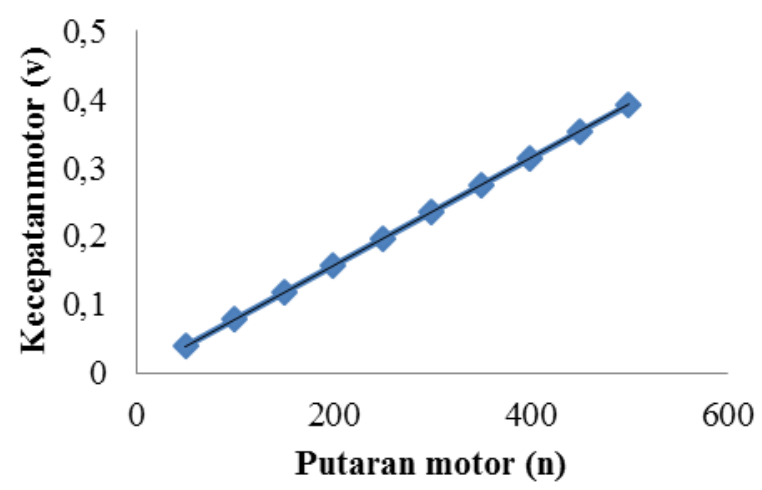

Gambar 11. Grafik hubungan antara putaran mesin dengan daya yang ditransmisikan

Berdasarkan grafik di atas dapat dijelaskan bahwa semakin besar putaran mesin maka daya yang dihasilkan juga besar. Karena putaran yang besar mampu menghasilkan kecepatan yang tinggi yang pada gilirannya akan meningkatkan daya yang dihasilkan.

Daya yang dihasilkan oleh motor karena akibat torsi pada motor tersebut memiliki nilai yang berbeda dengan daya yang ditransmisikan pada pengangkut sampah. Untuk lebih jelas, perbandingannya dapat dilihat pada Tabel berikut:

Tabel 1. Perbandingan daya motor dengan daya yang ditransmisikan

\begin{tabular}{ccc}
\hline No & Daya Motor $(\mathbf{K W})$ & Daya Transmisi $(\mathbf{K W})$ \\
\hline $\mathbf{1}$ & 0,52 & 0,26 \\
$\mathbf{2}$ & 0,47 & 0,23 \\
$\mathbf{3}$ & 0,42 & 0,21 \\
$\mathbf{4}$ & 0,37 & 0,18 \\
$\mathbf{5}$ & 0,31 & 0,15 \\
$\mathbf{6}$ & 0,26 & 0,13 \\
$\mathbf{7}$ & 0,21 & 0,10 \\
$\mathbf{8}$ & 0,16 & 0,08 \\
$\mathbf{9}$ & 0,10 & 0.05 \\
$\mathbf{1 0}$ & 0,05 & 0,03 \\
\hline
\end{tabular}

Dari Tabel tersebut didapatkan bahwa daya yang ditransmisikan lebih rendah dari pada daya yang dihasilkan motor karena tidak semua daya 
datri motor dikonversi sepenuhnya menjadi daya sistem atau pengangkut sampah. Hal ini disebabkan karena adanya faktor-faktor yang dapat mereduksi daya tersebut sebelum sampai pada sistem. Faktor-faktor tersebut adalah adanya getaran, beban sistem dan proses mekanik lainnya.

\section{Kesimpulan}

- Pada penelitian ini kami berhasil merancang model robot pengangkut sampah pada kanal sempit. Adapun bagian bagian dari robot tersebut adalah:

Rumah robot, rangka pengangkut sampah, pengangkut sampah berupa jaring-jaring dan bilahan pipa, roda penggerak robot, talang sampah, rangakaian ARDUINO UNO, dan aki

- Pada penelitian ini kami berhasil merancang program penggrak robot dengan soft ware Arduino Uno. Pada program ini program memberi printah kerja pada sistem atau motor penggerak untuk menggerakkan rangka pengangkut sampah bergerak turun ke kanal mencari air. Di saat sensor air telah menyntuh air maka sensor akan mengirim ke program agar memberhentikan motor penggerak rangka tersebut. Bersamaan dengan itu program memerintahkan/mengirim sinyal ke motor penggerak pengangkut sampah agar berputar, sehingga pengangkut sampah bergerak menyaring sampah yang ada.

\section{Referensi}

[1] Ridho Azlam. 2006. Pengolahan Sampah Organik dan Anorganik. Bandung

[2] Pacchierotti, E., Christensen, H., Jensfelt, P. 2005. Human robot embodied interaction in hallway settings: a pilot user study. Paper presented at the IEEE international workshop on robot and human interactive communication. Nashville, USA, 2005

[3] Lewis F.L., Abdallah, C.T. and Dawson, D.M. 1993. Control of Robot Manipulators. Macmillan, New York

[4] Mester, G. 2009. Intelligent Mobil Robot Control in Unknown Environments, Intelligent Eng. Systems and Computational Cybernetics. Part I. Intelligent Robotics. Springer, Netherlands.

[5] E. Sariyildiz, and H. Temeltas. 2009. Solution of Inverse Kinematic Problem for Serial Robot Using Dual Quaterninons and Plucker Coordinates. IEEE/ASME, Singapore.

[6] Seraji, H, Howard, A. and Tunstel, E. 2001. Terrainbased Navigation of Planetary Rovers: A Fuzzy Logic Approach. Quebec, Canada.

[7] Xu, W.L, Tso, S.K. and Fung, Y.H.: Fuzzy Reactive Control of a Mobile Robot Incorporating a Real/Virtual Target Switching Strategy. 